\title{
Um percurso temático complexificado sobre horta: as contribuições das hipóteses de transição
}

\author{
Carla Sarmento Santos \\ UFABC, Universidade Federal do ABC/Mestranda no Programa de Pós graduação em \\ Ensino e História das Ciências e da Matemática. Santo André/SP. Brasil. \\ carla.santos@aluno.ufabc.edu.br \\ ORCID: https://orcid.org/0000-0003-0041-0328
}

\section{Fernanda da Rocha Carvalho}

UFABC, Universidade Federal do ABC/Doutoranda no Programa de Pós graduação em Ensino e História das Ciências e da Matemática. Santo André/SP. Brasil. carvalho.fernanda@ufabc.edu.br

ORCID: http://orcid.org/0000-0001-8481-5626

\section{Denise de Freitas}

UFSCar, Universidade Federal de São Carlos/Centro de Educação e Ciências Humanas. São Carlos/SP. Brasil.dfreitas2011@gmail.com ORCID: https://orcid.org/0000-0003-1575-3243

\section{Giselle Watanabe}

UFABC, Universidade Federal do ABC/Centro de Ciências Naturais e Humanas. Santo André/SP. Brasil. giselle.watanabe@ufabc.edu.br ORCID: http://orcid.org/0000-0002-3738-7160

[Recebido: 7 janeiro 2021. Revisado: 23 agosto 2021. Aceitado: 4 novembro 2021]

\begin{abstract}
Resumo: As questões socioambientais vêm sendo incorporadas no currículo, seja por demandas internas ou externas à escola. Por ter um caráter complexo e tratar de assuntos próximos da realidade, elas têm potencialidade para contribuir com uma formação mais crítica. Pautado nesses pressupostos, a partir de um percurso temático que trata do tema hortas, este artigo tem como objetivo discutir as possibilidades de inserção de assuntos com caráter mais complexo e crítico, orientados pelas hipóteses de transição. A pesquisa foi realizada em uma escola pública paulista, Brasil. Metodologicamente, pautada na Análise Textual Discursiva, identificam-se no percurso temático algumas hipóteses de transição que podem indicar espaços curriculares que promovam um conhecimento escolar mais complexificado. Dos resultados, notam-se que as hipóteses, por um lado, contribuem para a proposição de aulas mais próximas dos estudantes; e por outro, dá ao docente a oportunidade de incluir em suas aulas outras estratégias e reflexões, mobilizando conhecimentos que contribuem para a transição de um pensamento simples para outro mais complexo.
\end{abstract}

Palavras chave: Ensino de ciências; Complexidade; Hipóteses de transição; Percurso temático.

Una trayectoria temática compleja sobre el huerto: los aportes de las hipótesis de transición

Resumen: Las cuestiones socioambientales se han incorporado al currículo escolar, ya sea por demandas internas o externas de la escuela. Debido a que tienen un carácter complejo y tratan temas cercanos a la realidad, tienen el potencial de contribuir a una educación más crítica. A partir de estos supuestos, y de una trayectoria temática que aborda el huerto, este artículo tiene como objetivo discutir las posibilidades de insertar temas con un carácter más complejo y crítico, guiados por hipótesis de transición. La investigación se llevó a cabo en una escuela pública de São Paulo, Brasil. Metodológicamente, con base en el Análisis Textual Discursivo, se identifican algunas hipótesis de 
transición en la trayectoria temática que pueden indicar espacios curriculares que promueven un conocimiento escolar más complejo. De los resultados se observa que las hipótesis, por un lado, contribuyen a la proposición de clases más cercanas a los estudiantes; y por otro lado, brindan a los docentes la oportunidad de incluir en sus clases otras estrategias y reflexiones, movilizando conocimientos que contribuyan a la transición del pensamiento simple al más complejo.

Palabras clave: Enseñanza de las ciencias; Complejidad; Hipótesis de transición; Trayectoria temática.

Para citar este artigo: Santos, C. S., Carvalho, F. R., Freitas, D. y Watanabe, G. (2021) Um percurso temático complexificado sobre horta: as contribuições das hipóteses de transição. Revista de Educación Ambiental y Sostenibilidad 3(2), 2101. doi: 10.25267/Rev_educ_ambient_sostenibilidad.2021.v3.i2.2101

\section{Introdução}

As discussões acerca das interações entre ser humano e ambiente estão cada vez mais difundidas na sociedade, por exemplo nos meios de comunicação, que geralmente sinalizam para uma crise ambiental causada por diferentes contextos (políticos, culturais, econômicos etc.). Questões dessa natureza atingem as escolas, seja por ela estar imersa fisicamente em um problema socioambiental (localmente) ou por sofrer as suas consequências (globalmente). Diante disso, nos parece essencial refletir sobre o contexto atual e particular de cada escola (sua realidade, como salienta Freire, 1977; Costa et al., 2021) e abordar temas em que as interações nesses diferentes cenários sejam estabelecidas de forma mais clara, tanto do ponto de vista das tecnologias e ciências envolvidas quanto das relações sociais que se estabelecem. Nessa perspectiva, Watanabe \& Kawamura (2014) destacam que a Educação Ambiental (EA) deveria promover uma formação que vai além da reprodução dos discursos presentes nos livros didáticos, jornais, revistas e outros meios de comunicação, pautando-se na ideia da criticidade e da complexidade. Na perspectiva da criticidade, Guimarães (2008) e Loureiro (2008) argumentam que o modo como essa questão vem sendo inserida na escola pode inibir uma visão crítica por parte dos estudantes, desenvolvendo, portanto, um pensamento reducionista e simplificador.

Na perspectiva da complexidade, García $(1998,2004,2021)$ destaca que a EA traz em seu cerne preocupações como a forma de agir e lidar com o meio em transformação. Para ele, o desenvolvimento de uma EA mais complexa não deve ser isolada ou distanciada de outras esferas do conhecimento. Salienta, inclusive, que o processo ensino-aprendizagem deve conduzir à complexificação do conhecimento pautada por estratégias que consideram, por exemplo, as hipóteses de transição (Garcia, 2004). Essas hipóteses permitem compreender a construção do conhecimento escolar, indicando os obstáculos e facilitadores no processo de ensinar em sala de aula (Rodríguez-Marín, 2021; Rodríguez-Marín et al, 2014; Garcia, 1998, 2004).

As questões socioambientais aparecem nos documentos oficiais brasileiro, como a Base Nacional Comum Curricular (BNCC) (Brasil, 2017) que discute a necessidade do sujeito interagir com o meio, e os fenômenos naturais e artificiais, compreendendo suas relações. Já os Parâmetros Curriculares Nacionais (PCN) (Brasil, 1997) apontam para a construção do conhecimento interdisciplinar articulado com os aspectos social e cultural. Nesse sentido, propor aulas mais abertas vinculadas aos conceitos escolares que emergem do estudo socioambiental considerando, por exemplo, a construção de uma horta pautada pelos preceitos da permacultura, pode contribuir para uma formação científica escolar, sob a perspectiva da complexidade e criticidade. 
Considerando os aspectos supracitados, e a partir de uma proposta de aula identificada como percurso temático (Watanabe, 2008), este artigo discute as possibilidades de inserção de assuntos com caráter mais complexo e crítico, orientados pelas hipóteses de transição. Essas hipóteses são encontradas em um estudo sobre horta escolar. Elas orientam a construção do conhecimento mais aberto para interpretar e se adaptar à realidade de cada contexto.

\section{Fundamentação teórica}

Para a discussão que segue, apoiada em García $(1998,2004)$, consideramos que o conhecimento escolar desenvolvido em sala de aula deve ir além da distinção entre conhecimento científico e cotidiano. Ele pode tratar de questões, soluções e organização das ideias, promovendo a transição de um pensamento simples para outro mais complexo, e se pautar por um trabalho em sala com temas abertos, tais como os socioambientais.

Dentre os pressupostos da EA tem-se o de que a sua função não é apenas a de desenvolver determinados hábitos ambientalistas, mas também a de proporcionar uma mudança de pensamento e conduta, que permita mostrar aos alunos que não existe uma verdade absoluta sobre a preservação do meio ambiente ou ações únicas para resolução dos problemas socioambientais, mas sim uma verdade relativa que pode ser construída e reconstruída. Como aponta García $(2004,2021)$ uma prática que pretende a conscientização mas que é trabalhada sem vínculo às outras esferas do conhecimento, fomenta a ideia de que os problemas ambientais são pontuais e não fazem parte de um sistema como um todo; da mesma forma que quando o enfoque é voltado quase que exclusivamente para ou sobre o meio ambiente gera uma educação pontual na natureza, tornando-se insuficiente. Dessa forma, trabalhar os problemas socioambientais de forma desconectada aos aspectos sociais, políticos, culturais e históricos, por exemplo, promove uma alienação, uma vez que suprime a reflexão sobre a ação.

Para Guimarães (2008) e Loureiro (2008), subsidiada pelas ideias freireanas, a formação de um cidadão capaz de atuar no meio social requer um ensino pautado nos aspectos que vão ao encontro do que se denomina de Educação Ambiental Crítica. Para os autores, o modo como a educação vem sendo desenvolvida ao longo dos anos está relacionado com a organização e com os objetivos da sociedade vigente, o que nos leva a incorporar reflexões que lidem com construção histórica influenciada pelas relações sociais, culturais, políticas e econômicas. Ou seja, uma EA do ponto de vista da criticidade deve ser tratada de forma que o estudante compreenda os processos que influenciam o meio em que vivem e não simplesmente estudem conceitos científicos sobre o ambiente. Assim, embora se reconheça a importância de trabalhos sobre a temática ambiental desenvolvidos na escola é importante destacar que a EA, no contexto escolar, deverá, para além de focalizar os problemas ambientais cotidianos e indicar a busca de soluções pontuais e individuais, discutir as questões socioambientais vinculadas aos conhecimentos científicos e às outras esferas do conhecimento, tais como as culturais, econômicas e políticas. Dessa forma, é possível formar um sujeito pautado por condutas e reflexões mais críticas (Freire, 1977) que, por sua vez, estará mais próximo dos problemas de sua realidade; capaz de lidar com situações que demandam um posicionamento mais democrático e justo. 
Já a complexidade prevê o rompimento de uma visão de mundo estático e simplificador, em contraposição a uma outra visão, mais dinâmica e articulada com essas esferas do conhecimento. Como apontado por García $(1998,2021)$, o desenvolvimento de uma EA nessa perspectiva pode promover uma cultura que trata das questões voltadas ao meio ambiente com base na ética ambiental e nas habilidades em resolver e solucionar problemas. Essa cultura alternativa busca formar um indivíduo capaz de compreender e zelar pela preservação do meio, pautando-se pela concepção sistêmica do meio. Segundo o autor,

O conteúdo de EA deve ser um meio para promover uma cultura alternativa do modelo social dominante. Uma cultura que integra, de forma equilibrada, a concepção sistêmica do meio, da ética ambiental e da capacidade de resolver problemas socioambientais. Uma cultura que leva em conta as contribuições das ciências - da ciência da natureza e da ciência sociais - e dos aspectos ideológicos. (García, 2004. p. 197).

Em convergência a essa discussão, a conscientização e responsabilidade, como salienta Garcia (2004), são elementos fundamentais de uma educação para a complexidade. A construção do conhecimento deve ser um processo social, baseado na interação, valores éticos e culturais, aspectos preconizados na permacultura.

A permacultura não se resume apenas a novas técnicas de manejo da terra, mas engloba saberes diversos, estimula a criatividade, reflexões sobre a prática e proporciona novas perspectivas sobre as relações entre seres humanos e natureza. Configura-se como uma possibilidade de enriquecimento das ações escolares ao também considerar as inter-relações do conhecimento escolar com aspectos socioambientais, socioculturais e históricos. A construção da horta escolar, nesse contexto, incorpora as relações éticas (Mollison \& Slay, 1998; Holmgren, 2013), e promove uma percepção sistêmica e dinâmica.

Por fim, destaca-se que a EA aqui preconizada deve mediar de forma contextualizada as reflexões acerca das questões socioambientais. Essa forma de lidar com a questão contribui para a construção da autonomia do sujeito, possibilitando ainda o desenvolvimento de um pensamento complexo (Morin, 2007).

\section{Hipóteses de transição e conhecimento escolar complexificado}

O conhecimento escolar demanda propor questões, assim como pensar possíveis soluções e organizar as ideias dos sujeitos de forma a alcançar pensamentos mais críticos. Como defendido por Garcia (1998, 2004, 2021), é necessário construir um conhecimento que contribua para a formação de um sujeito em constante transformação e que leve em consideração a existência de uma interação contínua entre as esferas de conhecimentos. Para ele, o conhecimento cotidiano se caracteriza como um conhecimento construído pelo indivíduo, diante da necessidade de entender o meio do qual faz parte, criar estratégias pautadas por observação e informação adquiridas independentemente de estudos, pesquisas, reflexões ou aplicações da ciência. Embora o conhecimento cotidiano esteja ligado aos problemas práticos resolvidos pelo sujeito, as respostas dadas a esses problemas não são comuns visto que são embasadas pelas ideias vigentes em determinados grupos sociais e culturais 
ao qual pertence. Isso significa que em uma mesma sociedade é possível identificar respostas mais simples e outras mais complexas frente a um mesmo problema.

0 conhecimento científico refere-se àquele elaborado por grupos de cientistas ou pesquisadores individuais, construído por meio de modelos científicos que investigam ou explicam fenômenos da natureza. 0 seu desenvolvimento é caracterizado pela produção de pesquisas pela academia, que pode se dar em diferentes ambientes, como laboratórios ou campos, por cientistas isolados ou em equipes de pesquisas (Carvalho, 2016; García, 1998, 2021; Lopes, 1994). 0 método básico de como deve ser o procedimento a fim de produzir conhecimento dito científico consiste em identificar teorias, leis ou técnicas para interpretar ou desenvolver os modelos. É importante ressaltar que o conhecimento científico não se reduz apenas a observação, a experimentação e ao uso de fórmulas e equações, embora sejam elementos básicos nesse processo, mas a produção de conhecimento se dá no âmbito de uma comunidade científica por meio das organizações e elaborações científicas partindo de problemas concretos, num determinado momento histórico. Salienta-se ainda que a ciência pode caracterizar-se por um processo de construção e desconstrução, permeada por rupturas e incertezas (Morin, 2007).

A partir dessas ideias, para definir o conhecimento escolar (Carvalho, 2016; García, 1998; Lopes, 1994) incorpora esses dois conhecimentos (científico e cotidiano), dando ao conhecimento escolar elementos que vão caracterizar sua própria natureza, pautadas pela transição dos conhecimentos cotidiano e científico. 0 conhecimento escolar é tido

[...] como integração de outras formas de conhecimento e como o enriquecimento de conhecimento cotidiano, que suporta, a partir de uma perspectiva sistêmica, a continuidade entre as diferentes formas de conhecimento, o que propõe a existência de um gradiente duplo: a partir do cotidiano com o científico, com uma ampla variedade de tipos de conhecimento intermediário, do simples ao complexo, dentro de cada uma das diferentes formas de conhecimento. (García, 1998. p. 30)

Nota-se que o conhecimento escolar traz possibilidades para a promoção de uma visão mais abrangente do mundo, capaz de construir argumentos mais complexos acerca das ideias que já possuem sobre determinado assunto (conhecimento cotidiano), baseando-os em conceitos da ciência (conhecimento científico) e tornando protagonista da sociedade e ativo diante de problemas sociais (outras esferas do conhecimento).

Esses argumentos mais complexos estão submetidos a um processo de reorganização contínua das próprias ideias dos alunos. Para García (1998), essa reorganização é um processo aberto que não pode ser reversível, pois está em evolução. Logo, o conhecimento não é algo pronto que se dá para o educando, mas é construído no contexto escolar. Para o autor esse processo passa por diferentes hipóteses de progressão e de transição (García, 1998), discutidas também por Rodriguez-Marín (2021). As hipóteses de progressão referem-se ao argumento construído pelo aluno; pautado pelas interações ou reorganizações possíveis e seguidas por uma reestruturação que corresponde à sistematização das suas concepções. As hipóteses de transição, referem-se àquilo que o professor foi efetivamente capaz de planejar/aplicar para suas aulas (García, 1998); logo, "se referem ao sucessivo estado 
do qual passa um indivíduo na evolução de um determinado conhecimento, alcançando o limiar, a um grau de abstração" (García apud De Vecchi, p.149, 1998). As hipóteses de transição ainda podem ser consideradas um plano metodológico (Rodríguez-Marín et al., 2014) com dupla utilização: (i) como orientação para o docente compreender o desenvolvimento dos conteúdos trabalhados em sala de aula; e (ii) como orientação para o docente analisar, compreender e detectar as hipóteses de progressão manifestados pelos alunos durante a construção de suas ideias.

As hipóteses de transição têm uma natureza flexível, pois reconhecem a diversidade dos argumentos encontrados pelos alunos ao longo do desenvolvimento do conhecimento escolar e, por outro lado, reconhecem as dificuldades enfrentadas no ambiente escolar. Elas se caracterizam por ser um sistema aberto capaz de interpretar e se adaptar às distintas realidades. 0 educador

(...) tem de ter uma hipótese de trabalho sobre o que pode acontecer no processo de ensino e aprendizagem, e essa hipótese não deve referir-se, necessariamente, a uma mudança progressiva e linear, mas uma transição mais aberta a partir de um nível de formulação para outro, também consideram-se contratempos e mudanças não previstas inicialmente. (Rodríguez-Marín et al., 2014, p. 307).

As hipóteses de transição são, portanto, um meio de orientar a ação docente antes, durante e após o desenvolvimento das aulas, contribuindo ainda para a compreensão das hipóteses de progressão a partir de cada argumento construído ou reorganizado pelos alunos frente a um conhecimento específico. Vale ressaltar que esses dois conceitos - hipótese de transição e hipóteses de progressão - são dependentes, havendo uma relação estreita entre eles: o educador planeja suas atividades e consequentemente considera a evolução das ideias dos alunos. Do ponto de vista complexo, as hipóteses de progressão identificam as interações ou reorganizações dessas ideias ao longo do processo de aprendizagem.

Carvalho (2016) destaca que com essa ferramenta torna-se possível identificar conexões nos argumentos dos alunos, seja individual ou coletivamente. Os argumentos para explicar determinado tema aparecem como resultado da interação direta ou indireta dos alunos com o sistema (aula de ciências, escola, cotidiano, docente etc.). Salienta que os argumentos iniciais do sujeito, quando participam de uma proposta de aulas mais complexa, encontram-se em um menor grau de complexidade; no entanto, após iniciar uma reflexão um pouco mais sistematizada do ponto de vista do conhecimento escolar, nota-se que os discursos de parte dos alunos vão se tornando mais complexificados, pois eles têm a oportunidade de se aproximar de outras esferas do conhecimento. Um dos principais apontamentos dessa abordagem refere-se a consideração de que o conhecimento desenvolvido pelos alunos não se estabelece de forma contínua e sequencial, visto que segue uma evolução dentro do seu tempo, ou seja, as ideias dos estudantes são organizadas ou reconstruídas constantemente ao longo de uma proposta de aulas. Assim, por exemplo, os alunos podem "pular" alguns níveis de conhecimentos; se estabilizar em determinado nível; ou ainda atingir o grau máximo de complexidade. Nessa dinâmica ainda há de considerar que os sujeitos podem não permanecerem nesses níveis por muito tempo, em especial, quando as ligações são mais fracas. 


\section{A trajetória da pesquisa e sua metodologia}

A construção da horta escolar foi parte de um projeto de pesquisa realizado em uma escola pública na periferia do grande $A B C$, São Paulo, Brasil, sendo parte de um projeto de pesquisa desenvolvido no GrECC $^{1}$ (Grupo de Ensino de Ciências e suas Complexidades). Inspirou-se em projeto desenvolvido em Sevilla/ Espanha, no CEIP Olivar de Quinto que começou como uma atividade pontual e extra curricular, mas de desenvolveu em um projeto que expandiu para o bairro e ganhou apoio da associação Montequinto Ecológico promovendo ações de agricultura ecológica nas escolas (Rodríguez-Marín et al., 2017).

Foram organizadas propostas de aulas, identificadas como percurso temático (Watanabe, 2008), sobre a construção de hortas pautadas por preceitos da permacultura. As atividades na escola envolveram duas professoras de ciências e uma de biologia, além de 46 estudantes dos sextos e sétimos anos do ensino fundamental; divididos entre a ação de (i) construção da hora e preparo do espaço, assim como pesquisa na sala de informática; e (ii) construção dos percursos temáticos.

A (i) construção da horta envolveu alunos, professoras, comunidade externa (por meio de doação de terra, areia, adubo e caixotes), representantes do grêmio estudantil, coordenadora pedagógica e o GrECC. Quanto às plantas cultivadas na horta, elas surgiram das demandas da própria escola a partir de diálogo com as merendeiras, indicando as hortaliças, como "cebolinha" Allium schoenoprasum, "coentro" Coriandrum sativum e "couve" Brassica oleracea, dentre outros. Também foram utilizadas algumas Plantas Alimentícias Não Convencionais (PANC), popularmente conhecidas como "capuchinha" Tropaeolum majus e "peixinho" Stachys byzantina.

Em (ii) foram construídos percursos temáticos sobre hortas a partir das estruturas conceitual e temática (Watanabe, 2008). Essa construção envolveu as professoras de ciências e biologia da escola, assim como o Grupo de Ensino de Ciências e suas Complexidades (GrECC). A estrutura conceitual (Figura 1) refere-se à organização dos conceitos científicos escolares que se relacionam com o tema central. Nesta estrutura estão identificados conceitos de áreas distintas do conhecimento. Por exemplo, do ponto de vista da Física estão indicados aspectos da calorimetria; da relação entre óptica física e geométrica ao se tratar da bioenergética da vegetação das hortas; e reflexões sobre trocas e fluxo de energia. Na Química estão indicados os tipos de solo e ciclos geoquímicos para tratar a dinâmica local e global do sistema horta; e as relações entre o uso de adubos químicos e pesticidas em monoculturas para aumento da produção de alimentos e as consequências dessa prática à saúde. Na Matemática estão indicados os estudos sobre proporção e espaçamento entre os alimentos no que diz respeito a pensar de forma mais eficiente para que ocorra irrigação e crescimento adequado da vegetação, sem que haja sobreposição e competição exagerada entre elas, constituindo para um sistema harmonioso e duradouro. Na Biologia estão indicados o aumento da produtividade com uso de transgênicos relacionados também às monoculturas e acesso ao alimento de qualidade; e discussões sobre compostagem e biomagnificação. Na Ciências Sociais estão indicadas as relações entre as práticas de

\footnotetext{
${ }^{1}$ O Grupo de Ensino de Ciências e suas Complexidade iniciou-se em 2012, com a intenção de propor aulas complexificadas. Neste grupo fazem parte alunos da Universidade Federal do ABC e conta com a participação de professores da escola básica da rede pública e particular.
} 
desperdício de alimento e compostagem articulados à distribuição de riquezas e reforma agrária nas sociedades brasileira e mundial e as consequências na geração de energia metabólica.

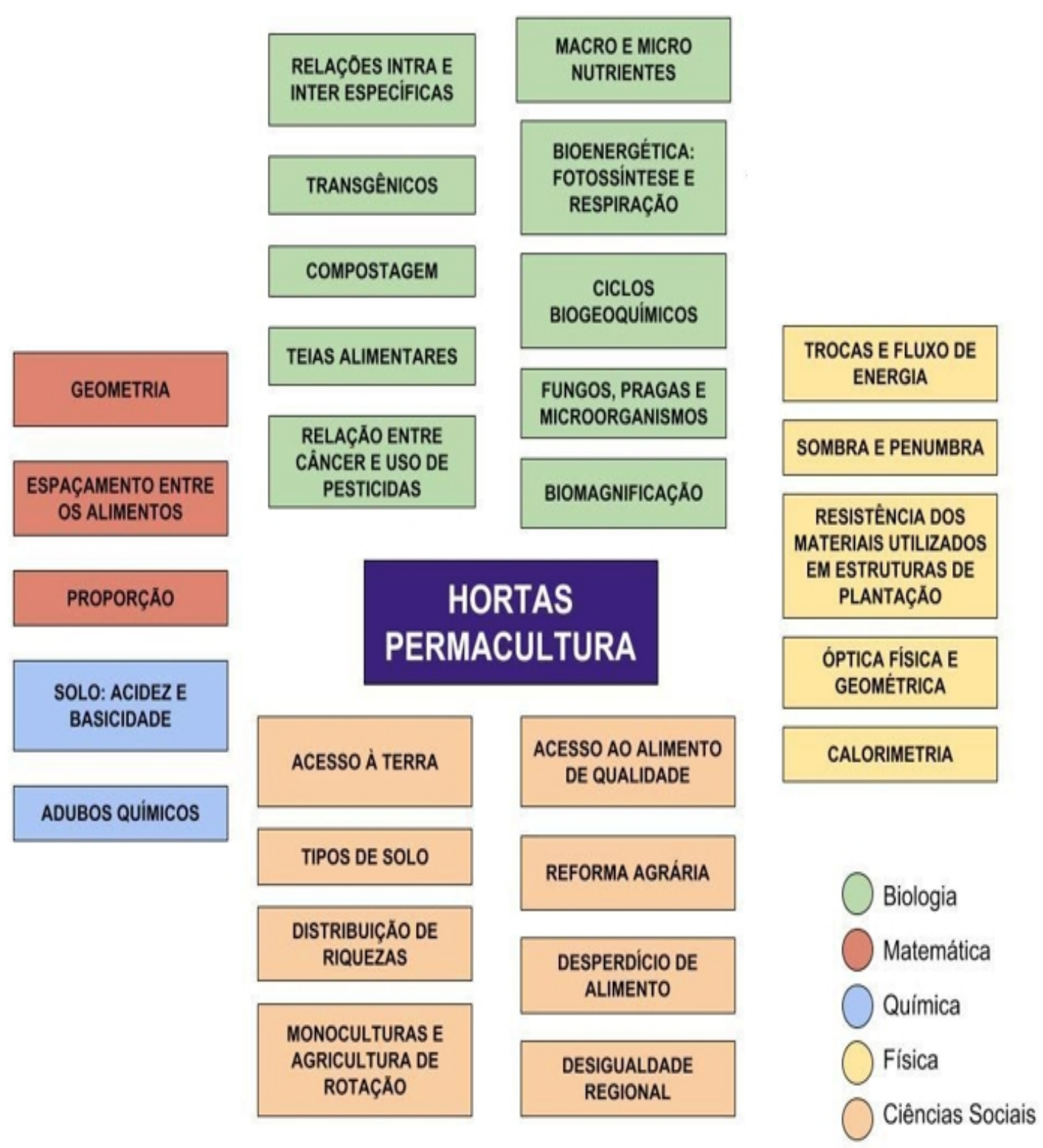

Figura 1. Estrutura conceitual sobre hortas e preceitos da permacultura. Elaboração própria.

A estrutura temática (Figura 2) trata-se de uma organização de assuntos gerais vinculados, por exemplo, aos aspectos políticos e culturais, associados ao tema horta e preceitos da permacultura. Essa estrutura teve sua organização proposta a partir das interações entre o GrECC e as professoras da escola. 


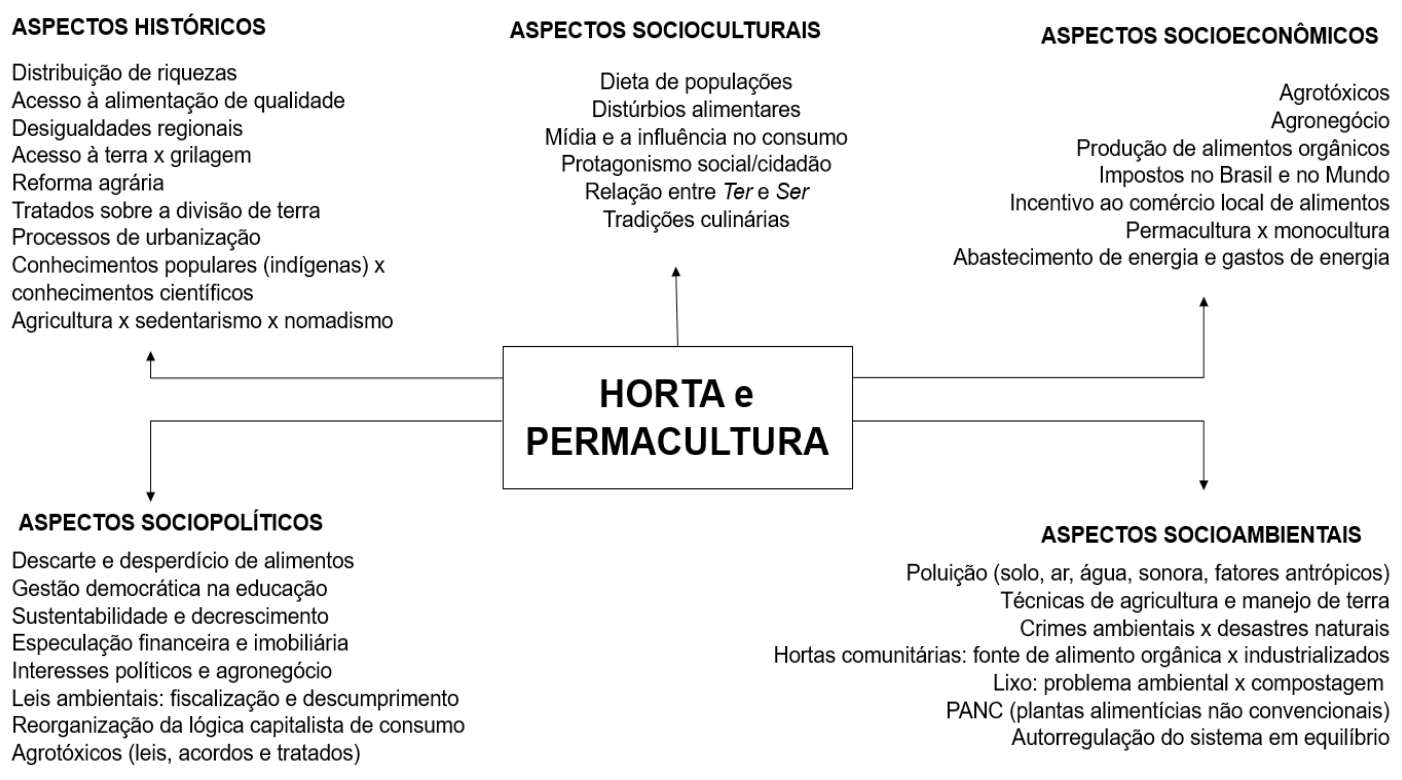

Figura 2. Estrutura temática sobre hortas e permacultura. Elaboração própria.

$\mathrm{Na}$ estrutura temática estão identificados aspectos de distintas esferas do conhecimento dispostos em "blocos". 0 bloco Aspectos Históricos traz reflexões sobre distribuição de riqueza e acesso à alimentação. 0 bloco Aspectos Sociopolíticos aborda elementos da sustentabilidade e decrescimento do ponto de vista das leis, fiscalizações e tratados políticos, além da gestão democrática na educação. 0 bloco Esfera Sociocultural apresenta as tradições culinárias e as relações entre ter e ser. 0 bloco Aspectos Socioeconômicos traz pontos que procuram repensar a forma de consumir, tratando do incentivo ao comércio local, o abastecimento e gastos de energia. 0 bloco Aspectos Socioambientais traz reflexões que procuram tratar dos problemas ou questões socioambientais enfrentados no cotidiano.

Já um percurso temático original (Figura 3) envolve escolhas realizadas com base nas estruturas temáticas e conceituais, ou seja, refere-se à possível organização da proposta de aulas. Assim, não se trata de um roteiro bem definido, mas um conjunto de possibilidades a serem selecionadas por professores a fim de organizar suas aulas considerando, por exemplo, a disponibilidade de aulas de ciências, a dinâmica da sala e dos espaços curriculares na qual a proposta seria aplicada. Para elaboração deste percurso, considerouse elementos dos Aspectos Históricos e Socioambientais (presentes na Figura 2) e os conceitos resistência em materiais utilizados em estruturas de plantação, proporção, tipos de plantas, cultivo e espécies de sementes e mudas (presentes na Figura 1). 0 desenvolvimento do percurso propunha um diálogo inicial com os estudantes e as professoras da escola, em especial, sobre o porquê da construção da horta na escola e a importância dessa ação envolvendo a comunidade (Aspectos Históricos). Os alunos foram convidados a investigar e conhecer os tipos de plantas e PANC (Aspecto Socioambiental) que iriam compor a horta. Durante a prática, optou-se em discutir a função dos caixotes, tratando de sua resistência, formato para comportar as hortaliças e os tratamentos necessários para suportar o plantio. Nessa etapa, os estudantes puderam lixar, envernizar, forrar com sacos plásticos para evitar vazamentos e compreender a camada de drenagem feita com areia. Outro momento importante durante as aulas foi a discussão sobre proporção matemática entre a terra vegetal, areia e o substrato a ser utilizado, essa reflexão contribuiu para o conhecimento no aspecto do cultivo e a importância da rega para a manutenção da horta. 


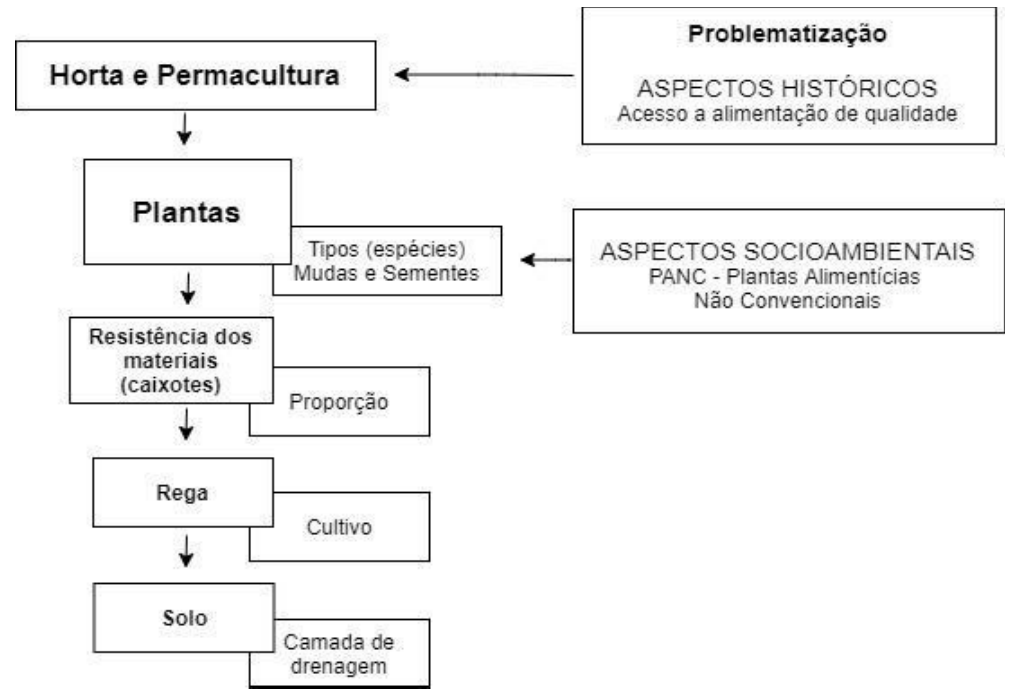

Figura 3. Percurso temático original. Elaboração própria.

É no percurso temático que foram obtidos os dados para essa pesquisa. Ou seja, a partir dele foi possível incorporar outras atividades/ações/reflexões por meio das hipóteses de transição. A intenção com isso foi enriquecer as aulas, tornando-as mais críticas e complexas. Para analisar os dados tomou-se os pressupostos da Análise Textual Discursiva (Moraes \& Galiazzi, 2007), que considera os significados construídos em um conjunto de textos enquanto um processo de auto-organização de novas compreensões. Foram seguidas as etapas: unitarização - realização da fragmentação de trechos dos estudos que fazem referência implícita ou explícita a elementos que apresentam relação com complexidade (García, 1998; Morin, 2007) e a criticidade (Freire, 1977; Guimarães, 2008; Loureiro, 2008), emergindo assim, unidades de significado; categorias temáticas - agrupamento das unidades de significado segundo suas semelhanças semânticas; e comunicação - elaboração de textos descritivos e interpretativos (metatextos) acerca das categorias temáticas. As categorias estão expressas nas quatro hipóteses de transição descritas na Figura 4.

\section{Resultados: percurso temático complexificado construído a partir das hipóteses transição}

A partir do percurso temático original (Figura 3) foram identificados outros aspectos que, pautados nos níveis de transição, podem promover um ensino mais complexo e crítico. Esse novo percurso será identificado como percurso temático complexificado (Figura 4). Vale destacar que os elementos indicados nas hipóteses de transição não devem ser compreendidos ou tratados simplesmente pela adição dos mais discutidos, mas compreender as interações, analisar e sistematizar o processo de aprendizagem em sua plenitude. Em outras palavras, as hipóteses de transição aqui sugeridas partem tanto das incomodações das professoras da escola quanto das vivências das pesquisadoras (autoras deste artigo). A partir das considerações sobre o percurso original é que foi possível identificar outros espaços para aprofundar o conhecimento escolar. De modo geral, as interações propostas nas hipóteses trazem uma discussão sobre horta e suas relações com a presença humana, cultural e científica. Desse ponto de vista, a complexidade também consiste na complementaridade das relações naturais, históricas e sociais, que interagem, entrecruzam-se e transformam-se, embora mantenham certas especificidades. 


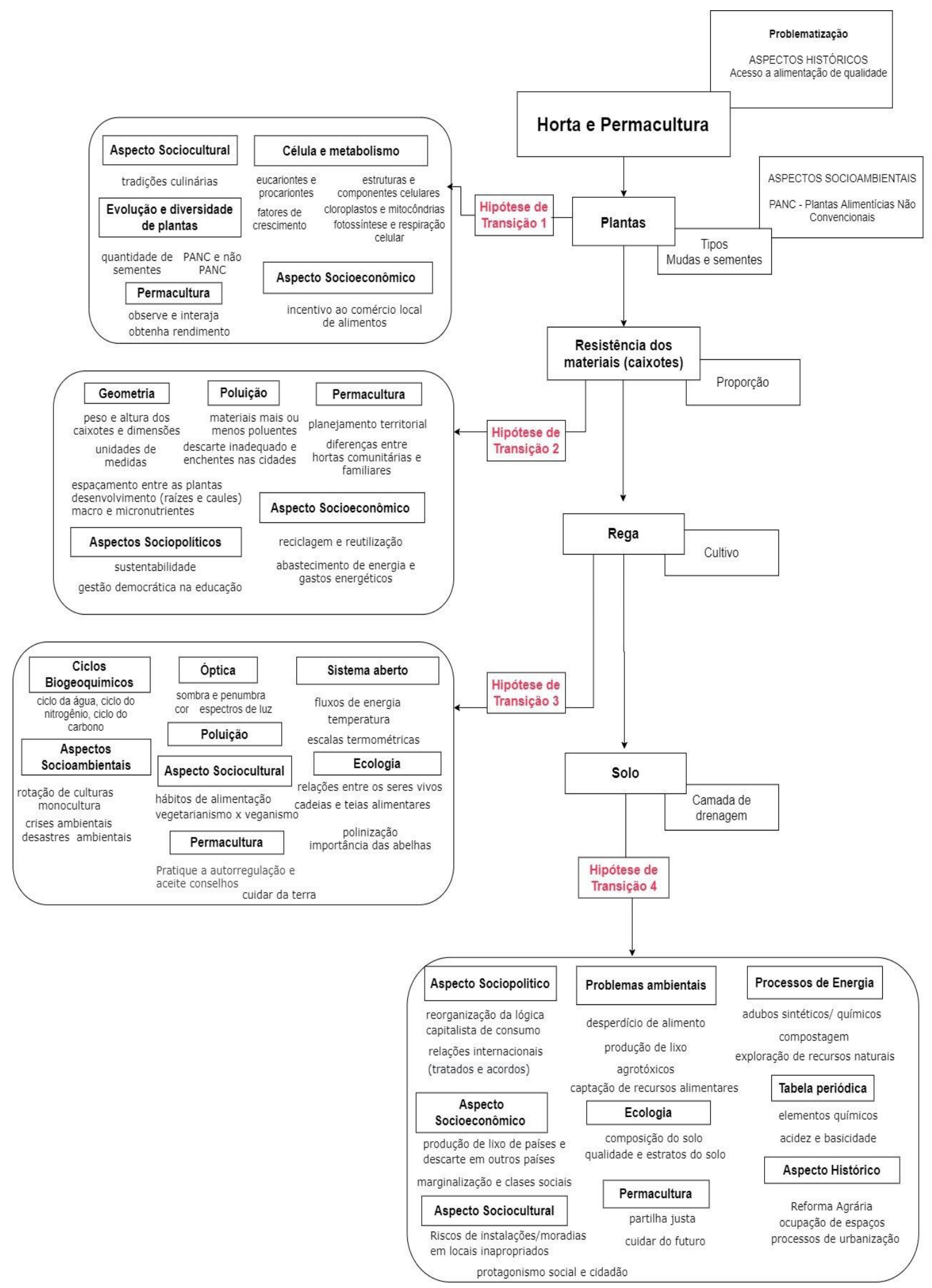

Figura 4. Percurso temático complexificado. Elaboração própria. 
Do ponto de vista dos aspectos temáticos, neste percurso são indicados assuntos mais gerais e abrangentes. Por exemplo, no âmbito econômico é possível discutir o uso dos agrotóxicos, a expansão de agronegócio e os impactos no desenvolvimento social; no âmbito histórico, propor discussões sobre reforma agrária e o impacto na ocupação territorial nas cidades (marginalizados e centrais); e no âmbito ambiental, tratar das questões acerca da poluição, diferenças entre os crimes ambientais e desastres naturais ou até mesmo discussões sobre a autorregulação em sistemas de equilíbrio. São assuntos relacionados ao tema que permitem reflexões que partem de problemáticas tanto locais quanto globais, articulados entre si. Esse percurso traz alguns subsistemas que podem indicar diferentes níveis de abordagens (grau de aprofundamento do conhecimento escolar) e aproximações com outras esferas do conhecimento. No caso das aproximações, é possível, por exemplo, considerar as questões de natureza sociocultural e tecnológica ao tratar das diferentes técnicas usadas pelos distintos povos indígenas da América Latina no cultivo de seus alimentos (gama muito grande de tipos/espécies de milho, arroz e batatas etc.).

O percurso temático complexificado considera quatro hipóteses de transição como elementos que indicam os pontos nos quais as aprendizagens fundamentais têm potencial para acontecer, dando ao docente a possibilidade de enxergá-las a tempo de fazer ajustes necessários durante as aulas. Vale ressaltar que as hipóteses de transição foram estruturadas considerando distintos graus de complexidade; em outras palavras, a hipótese 1 é menos complexa que a hipótese 3. Isso pode ser notado com o aumento das relações estabelecidas entre conceitos-conceitos e conceitosesferas do conhecimento; além da profundidade conceitual ampliada.

A hipótese de transição 1 está ligada à concepção conceitual, pautando-se no entendimento da Citologia. Nessa perspectiva, discussões sobre a planta podem iniciar a partir de um resgate sobre célula e metabolismo para então tratar dos possíveis elementos sobre evolução e diversidade das plantas. 0 trabalho na sala de aula com esses elementos pode incorporar aspectos mais locais e específicos (uso de plantas no cotidiano) ou mais globais e geográficas (plantações em diferentes regiões do Brasil). 0 conhecimento indicado nessa hipótese pode tornar-se mais complexificado ao incorporar reflexões que incluam aspectos socioeconômico e sociocultural. Por exemplo, ao tratar da relação do consumo de planta por cultura, planta usada na medicina ou energia gasta no plantio. Ao tratar da permacultura, os conceitos observe e interaja, destaca as relações livres e harmônicas entre natureza e pessoas e interpretações de métodos tradicionais de uso da terra, e obtenha rendimento destaca o pensamento de autossuficiência do sistema e plantação de alimentos e plantas úteis àquele espaço.

A hipótese de transição 2 aborda uma perspectiva mais integradora aos conceitos científicos escolares - Ecossistema e a Geometria (perspectiva da Matemática). As discussões nesta perspectiva podem ter como foco os problemas do uso de materiais não apropriados para o plantio, materiais que poluem o solo e água e a decomposição dos materiais sugeridos para a aula com foco na prática. Especificamente, na aula prática é possível tratar os conceitos de poluição e permacultura, de forma a tornar a discussão mais complexa ao considerar o processo dinâmico em que todos os materiais usados no dia-a-dia estão submetidos (reciclagem, descarte e poluição). Essa abordagem pode contribuir para incorporar, do ponto de vista da Matemática, discussões sobre quantidade de sementes, o peso das estruturas (caixotes), as 
unidades de medidas de litros e quilograma para a água e a terra, respectivamente. Também pode integrar outras esferas do conhecimento tais como aspectos político e econômico. Por exemplo, é possível discutir situações sobre riscos a partir do questionamento "Como saber se o que comemos é seguro?", refletindo sobre a segurança alimentar; ou tratar de conceitos relacionados aos agrotóxicos considerando os resultados dos relatórios da OMS (Organização Mundial da Saúde).

A hipótese de transição 3 sugere o estudo, na Biologia, dos conceitos Ecossistema e Evolução; na Física, dos conceitos tratados na Ótica e na Termodinâmica. Trata-se de considerar a mudança evolutiva e irreversível do sistema, a partir da abordagem de sistemas abertos (na Termodinâmica: troca de calor, fluxo de energia e temperatura; na Ótica: cores para estudar a diversidade das plantas e seu cultivo). Considerando preceitos da permacultura, é possível discutir o princípio autorregulação e feedback (feedback sendo interpretado também por aceite conselhos) relacionados à energia disponível e circular em sistemas abertos. Ainda é possível ampliar discussões analisando as variedades de plantas e elementos mais resistentes e robustos para enfrentar longos períodos de estiagem. Considerando a Química e Física pode-se tratar do volume e fluxo de água necessários para o abastecimento de uma horta. Nessa discussão não se trata simplesmente de uma água que passa, mas que se transforma ao passar pelas camadas de drenagem. Essas discussões acerca dos ciclos biogeoquímicos (ciclo da água, ciclo do carbono e ciclo do nitrogênio) e a influência na composição do solo de diferentes regiões na produção de alimentos são fundamentais para apresentar os distintos ecossistemas. Vale ressaltar que a hipótese de trabalhar o ciclo Biogeoquímica transita entre a Biologia e a Química, que trazem elementos sobre os materiais formados por partículas minerais, ar, água e compostos orgânicos do solo. Quanto à relação entre conhecimento socioambiental e sociocultural é possível debater as convergências e divergências internacionais e acordos firmados entre os países, a exemplo do crédito de carbono.

Na hipótese de transição 4 encontram-se conceitos da Biologia, como Botânica e Ecossistema, articulados com as outras áreas do conhecimento. Especificamente, articulam-se a eles aspectos da Química, tais como velocidade das reações físicoquímicas celulares e a influência na degradação de compostos complexos nas hortas. Na perspectiva da Geografia é possível propor discussões a respeito de tipos de solo e processos de urbanização, marginalização e de classes sociais. Na perspectiva da Matemática é possível discutir questões sobre o espaçamento entre as plantas e a influência em seu desenvolvimento e estruturas; além de acesso aos macro e micronutrientes. Na perspectiva da Física é possível discutir a Energia a partir da compostagem e adubo, considerando a dinâmica dos sistemas naturais. Ao integrar as outras esferas do conhecimento - aspectos histórico, sociopolítico, sociocultural e socioeconômico - é possível abordar os riscos de instalações/moradias em locais inapropriados, descarte de lixos em lugares impróprios, quantidade de lixo gerado, e a integração ser humano com sistema planetário. Aspectos da permacultura, podem aparecer ao discutir, por exemplo, o estabelecimento de "limites para o consumo e reprodução, e redistribuir o excedente" (Holmgren, 2013, p.8) Essas discussões remetem à construção de habilidades atreladas às possíveis mudanças de comportamento e posturas, visando incorporar ações e atitudes no e para o meio ambiente. 


\section{Breves considerações}

Durante a construção da horta na escola foi notória a ampla participação dos estudantes, professoras, agentes escolares e comunidade. Esse comprometimento com o processo ensino-aprendizagem foi um dos pilares para a construção de um diálogo aberto com as professoras e os alunos. 0 percurso temático original (Figura 3) mostrou tanto a preocupação com os conceitos quanto com a prática, especialmente, no que se refere às discussões sobre as fontes básicas de alimentação. Esse percurso mostrou abertura para inserção de novas discussões o que, para nós, se refletiu no percurso temático complexificado, organizado a partir das hipóteses de transição. Esse outro percurso primou pelas interações possíveis com as outras áreas do conhecimento e por uma organização do conhecimento que saísse do pensamento simples para um outro mais complexo. Essa perspectiva é salientada por García (1998, 2021), ao indicar que o estudo da natureza da ciência não pode se resumir apenas ao conteúdo de ciência, devendo utilizar em seu corpo teórico um grande número de conceitos originados em outras áreas do conhecimento.

Dos resultados, nota-se a necessidade de estabelecer o conhecimento escolar em suas singularidades, de forma que seja possível reconhecê-lo em sala de aula com suas próprias dinâmicas. As singularidades estão presentes na ideia do próprio percurso, que serve para o público daquela escola. Em todo caso, as hipóteses de transição não são itinerários fechados e iniludíveis, pelo qual inevitavelmente se deve passar, de forma que cada professor siga mecanicamente um trajeto linear e ascendente. Pelo contrário, elas têm um caráter aberto e flexível, admitindo caminhos formativos sinuosos, contraditórios e divergentes; contemplando os ciclos e as flutuações que inevitavelmente se dão em todo o processo de aprendizagem. As hipóteses podem contribuir para que o professor tenha mais clareza acerca das dificuldades e possibilidades de trabalhos mais efetivos, capazes de promover uma educação mais crítica, complexa e reflexiva (Watanabe \& Kawamura, 2014).

Para a criação de um percurso temático nos parece fundamental que o professor leve em consideração as limitações e tempo de aprendizagem dos alunos, a visão de mundo que permeia a sociedade e a sua comunidade e os interesses e ideias dos alunos sobre o tema que será tratado. Essas reflexões podem trazer maior participação e interesse dos envolvidos. Acreditamos que considerando esses aspectos, é possível articular o ensino de ciências à formação de cidadãos mais críticos e, por outro lado, mais aptos a compreender a ciência como algo em construção e que segue modelos pautados por protocolos sérios e validados.

\section{Agradecimento}

Esse trabalho é parcialmente financiado pela Fundação de Amparo à Pesquisa do Estado de São Paulo (Fapesp) (processo no2018/19136-3); e pelos Ministério da Ciência, Tecnologia, Inovações e Comunicações (MCTIC) e o Conselho Nacional de Desenvolvimento Científico e Tecnológico (CNPq) (chamada 05/2019, processo no-440369/2019-3).

\section{Referências bibliográficas}

Brasil. Ministério da Educação. Secretaria de Educação Média. (1997). PCN Ensino Médio: Orientações educacionais complementares aos Parâmetros Curriculares Nacionais. Ciências da Natureza, Matemática e suas Tecnologias. MEC. 
Brasil. Ministério da Educação. Secretaria de Educação Média. (2017). BNCC - Base Nacional Comum Curricular. Ciências da Natureza, Matemática e suas Tecnologias. MEC.

Carvalho, F. R. (2016). As Hipóteses de progressão numa progressão numa proposta de aula complexificada sobre o tema aquecimento global. Dissertação de Mestrado do Programa Ensino, História e Filosofia das Ciências e Matemática/ UFABC/ Universidade Federal do ABC. São Paulo.

Costa, F. M. O., Santos, C. S., \& Watanabe, G. (2021). Alguns parâmetros da criticidade e da complexidade em propostas de aulas socioambientais presenciais e remotas. Revista Brasileira de Pesquisa em Educação em Ciências, e33276-1-25. https://doi.org/10.28976/1984-2686rbpec2021u947971

Freire, P. (1977). Pedagogia do oprimido. Paz e Terra.

García, J. E. (1998). Hacia una teoría alternativa sobre los contenidos escolares. Díada Editora S. L.

García, J. E. (2004). Educación ambiental, constructivismo y complejidad. Serie Fundamental, no 21. Díada Editora S. L.

García, J. E. (2021). Educación ambiental y Complejidad. Youtube. [Vídeo] SNEF 2021. https://youtu.be/g1xUqX-VqxY

Guimarães, M. (2008). Os caminhos da Educação Ambiental: da forma a ação. Papirus.

Holmgren, D. (2013). Os fundamentos da permacultura. (Tradução de Alexander Van Parys Piergili e Amantino Ramos de Freitas). FCA/Unesp

Lopes, A. R. C. (1994). O currículo e a construção do conhecimento na escola controvérsias entre conhecimento comum e conhecimento científico. A. F. B. Moreira (org). Conhecimento Educacional e Formação do Professor. (pp. 39-52). Papirus

Loureiro, C. F. B. (2008). Caminhos da educação ambiental: da forma a ação, 3aa edicão. SP.

Mollison, B., \& Slay, R. M. (1998). Introdução à Permacultura. (Tradução de André Luis Jaeger Soares). MA/SDR/PNFC.

Moraes, R., \& Galiazzi, M. C. (2007). Análise Textual Discursiva. Editora Unijuí.

Morin, E. (2007). Introdução ao pensamento complexo, $3^{a}$ ed. Sulina.

Rodríguez-Marín, F. (2021). Ensino de ciências, complexidade e ambiente. Youtube. [Vídeo] SNEF 2021. https://youtu.be/Pt0Lh8psDZM

Rodríguez-Marín, F., Fernández-Arroyo, J., Puig-Gutíerrez, M., \& García-Díaz, J.E. (2017). Los Huertos Escolares Ecológicos, Un Camino Decrecentista Hacia Un Mundo Más Justo. Enseñanza de las Ciencias, N.ํㅡㄹ Extraordinario, 805-810.

Rodriguez-Marín, F., Fernández-Arroyo, J., \& García, J. E. (2014). Las hipótesis de transición como herramienta didáctica para la educación ambiental. Enseñanza de Las Ciencias, 32(3), 303-318. http://dx.doi.org/10.5565/rev/ensciencias.1137 
Watanabe, G. (2008). Elementos para uma abordagem temática: a questão das águas e sua complexidade. São Paulo. Dissertação apresentada ao Programa de PósGraduação em Ensino de Ciências, 198 f - Universidade de São Paulo. IFUSP.

Watanabe, G., \& Kawamura, M. R. (2014). Uma educação na perspectiva ambiental crítica, complexa e reflexiva. Revista Brasileira de Pesquisa em Educação em Ciências, 14 (2),

255-264, https://periodicos.ufmg.br/index.php/rbpec/article/view/4366 